\title{
Factors affecting energetic regulation of ovulation leading to birth seasonality in tropical and temperate subpopulations
}

Tess Johnson

\begin{abstract}
This essay details past and current research into the area of human birth seasonality. It focuses on the contrast in the mechanisms affecting the energetic regulation of ovulation $(E R O)$, which leads to birth seasonality between tropical and temperate subpopulations. In doing so, the seasonal nutritional conditions of females in sub-Saharan Africa and Nepal are evaluated, as well as the climatic and cultural factors that affect the hormonal balance that creates ERO. The essay finds that whereas decreased energy intake causes ERO and therefore birth seasonality in tropical agricultural/pastoral populations, it is increased energy expenditure that has the same effect in temperate agricultural/pastoral populations. Finally, current directions in the field of ERO are briefly explored as they relate to birth outcomes that remain unlinked to seasonality in industrialist populations.
\end{abstract}

\section{Keywords}

birth seasonality, ERO, agriculturalist, pastoralist

\section{Introduction}

Although seldom considered a species under seasonal reproductive control, humans in some populations have been shown to conceive and give birth at different rates depending on the season. Thus, around the world, patterns of 
conception rates—and hence birth rates—differ monthly according to seasonal factors, especially in agriculturalist and pastoralist populations (Ellison et al. 1989). This is observed most notably in traditional populations found in subSaharan Africa (e.g. Zairian Lese and Kenyan Turkana populations) and more temperate world regions such as Nepal and Arctic North America (e.g. Nepali Tamang and Arctic Inuit populations) (Ellison et al. 1989; Leslie and Fry 1989; Condon 1991; Panter-Brick 1996). Due to the dependence of tropical populations on both temperature and seasonal rainfall for food production, seasonality can have an immense impact on the energy balance of females in these communities, which in turn affects their fecundity (Bailey et al. 1992). Contrastingly, in temperate climates where crops are less dependent upon rainfall levels, workload generally plays a larger role in determining female energy balance. Although neither mechanism is entirely isolated, a generalisation can be made that environment tends to affect energy balance in tropical regions more, whereas workload tends to affect energy balance in temperate regions more. In both cases, fecundity is affected by changes in monthly ovulation according to energetic hormonal regulation. This energetic regulation of ovulation (ERO) allows women to conserve energy, which may be needed for their own somatic effort (as opposed to reproductive effort) in seasons when there is less food available or more work to be done (Panter-Brick et al. 1993). Thus, ERO is an important cause of birth seasonality, with the effect differing in tropical and temperate areas as a result of the factors of food availability and energy expenditure, respectively. I intend to explicate the contrast in the causes of ERO via comparison of southern African and Nepalese agriculturalist and pastoralist populations, both of which experience dramatic changes in female fecundity according to the above parameters. I will draw primarily from research performed by Ellison et al. (1989), Bailey et al. (1992), Leslie and Fry (1989) and Panter-Brick (1996) on birth seasonality within various subpopulations; however, reference will also be made to more recent literature, which tends to focus on various other subpopulations in industrial societies.

\section{The biology of seasonality}

The first study of birth seasonality dates back to the pioneering investigation of Swedish birth rates by Wargentin in 1767. Since then, an increasingly growing body of research concerning the phenomenon has led to the assertion by Ellison (2003) that birth seasonality is dependent on three categories of factors. These include social factors, such as age at marriage affecting 
intercourse timing; climate-based factors, which affect energy and hence conception probability; and epidemiological factors, which affect pregnancy success. The influence of proximate factors on fertility has been thoroughly investigated in anthropological demography. They are described by Bongaarts' (1978) model as mechanistic processes and anatomical reasons such as age at menarche, ovulatory rate and postpartum infecundability, which determine fertility itself. The mechanism behind ERO as a proximate determinant of fertility has been described by Berga and Naftollin (2012) as failure to ovulate according to alteration of the hypothalamic signals sent to the pituitary gland to cause progesterone and luteinising hormone secretion. While these hormones would ordinarily induce ovulation each month, their secretion is reduced due to the effects of metabolic signals on the hypothalamic processing centre. In addition to this, levels of estradiol are increased, giving negative feedback in the system. This reduces conception rates during periods when women would be less able to self-maintain energetically during pregnancy and lactation due to energy imbalance, which in turn affects birth rates, although intervening social and biological factors such as conceptus loss also contribute to birth rates.

Figure 1 describes the factors affecting energy imbalance in both tropical and temperate populations, and how this affects birth seasonality. The benefits of ERO in relation to the trade-off for somatic effort in place of reproductive effort are evident. Both offspring and, to an even greater extent, parental mortality is greatly increased when parental investment occurs in a sustenance-unstable environment (Rhinehart 2016). In fact, at the latter part of the gestation period, offspring take a full third of the mother's 'metabolic budget' as defined by her energy production and consumption (Ellison 2003). Thus, it is of much more benefit to the mother to invest in somatic effort and future reproduction rather than current reproduction. Under the conditions of natural selection, the ERO trait would have adapted and become more common over time due to the benefits in terms of survival and future reproduction for the parent (Rhinehart 2016). As will be further elucidated below, this has the effect of creating troughs in conception rates during periods of energy imbalance due to decreased rate of ovulation in favour of conserving energy for current somatic effort, and the opportunity to reproduce in future months when this energy imbalance may be later remedied. It should be noted that this effect on conception rates can be distinguished in the literature from the subsequent birth rates, which do not always correlate due to other factors such as conceptus loss. Thus, in the following case studies, emphasis is placed on whether 'seasonality' refers to conception or birth. 


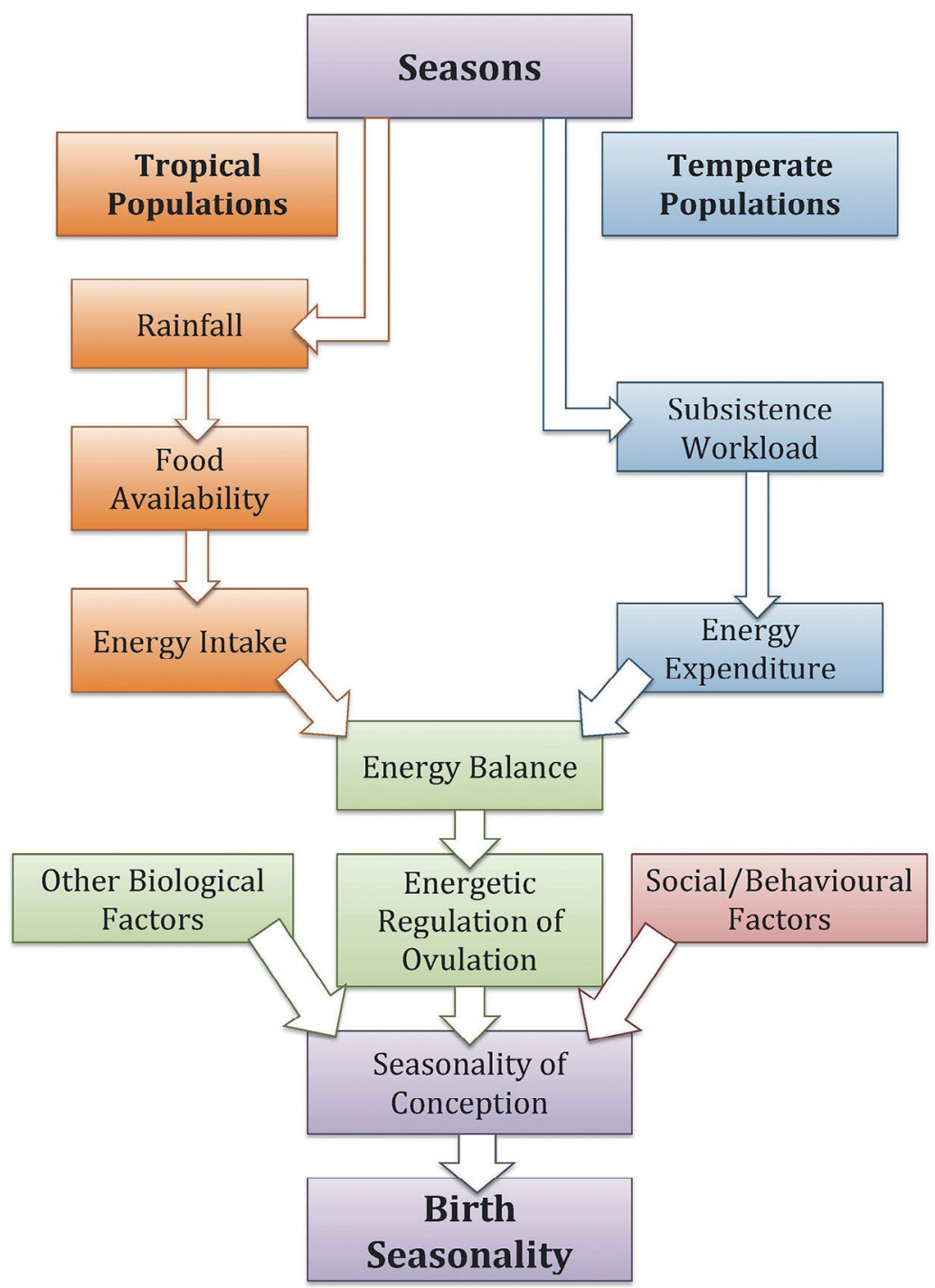

Figure 1: Flow diagram depicting select biological factors affecting birth seasonality in tropical and temperate areas respectively Source: Author. 


\section{Tropical African populations}

Current knowledge regarding energetic regulation of ovulation in tropical sub-Saharan African populations is based on a significant amount of past research. Previous studies have looked at populations from Kenya (Leslie and Fry 1989), Tanzania (Bantje 1987), the Gambia (Moore et al. 1997) and, most notably, former Zaire (Ellison et al. 1989; Bailey et al. 1992). Although a more limited number of recent studies have been conducted, such as Philibert et al.'s (2013) investigation into seasonality in Mali, and Dorélien (2015) and colleagues's (2013) various studies in South Africa, these current applications of birth seasonality focus less on the fundamental causes and occurrences and more on the implications, and are thus of lesser importance here. Of greater note is that seasonality was found to have an effect on the conception rates of all of these sub-Saharan African populations to varying degrees. The most pertinent populations for study in this case are the Lese people of Zaire and the Turkana people of Kenya. These two populations rely on pastoralism and agriculturalism as their means of subsistence in tropical areas, and are therefore the most affected by fluctuation in rainfall (Leslie and Fry 1989; Bailey et al. 1992).

Studies performed on the Lese agriculturalists date from Ellison's work from 1986 to 1989, which centred around the seasonality of births, and a comparison between these ovulatory rates and those of a standard Western population. Bailey et al.'s (1992) later work built upon this scaffold in a more biological context. He investigated hormonal levels and ovulation during the peak and trough months of conception rate, and related this to female energy balance. In this context, energy balance is defined as net energy intake over expenditure. Together, these studies found that in the population of Lese agriculturalists, monthly ovulatory frequency fluctuated dramatically. Troughs occurred reliably during the hunger season, sometime between January and June each year. During this time, seasonal rainfall was low and food availability decreased until the harvest in late June. After this point, food availability was greatly increased and ovulatory frequency rose again. In Bailey et al.'s (1992) later study, it was determined that the ovulatory frequency decrease was due to a marked reduction in ovarian hormone levels, including progesterone, which prevented ovulation from occurring during the hunger season. Hormone levels correlated directly with energy balance, which became negative during the hunger season due to a decrease in energy intake, shown by a decrease in weight of 2 kilograms on average compared to the seasons of plenty (Ellison et 
al. 1989). Contrastingly, after the harvest ovulatory frequency reached a peak with progesterone levels rising as female energy balance became positive due to increased food availability. The subsequent increase in weight correlated with an increase in conception rate from the period late July to November (Bailey et al. 1992). Energy balance was also to some extent affected by higher energy expenditure due to the winter workload; however, this had a milder effect. Thus, emphasis here is placed on the effects of lower energy intake on ERO in this and other African populations.

Study of ERO in the pastoralist Turkana population of Kenya was performed in a similar manner and time period to that of Ellison et al. (1989) and Bailey et al. (1992) by Leslie and Fry (1989). Their findings concerning the seasonality of conception patterns in the population corroborated the findings described above. In fact, in their study fluctuations in conception rates were found to be even more extreme. Leslie and Fry's work (1989) showed a positive correlation between conception rates and rainfall, but with a lag time of a couple of months. Peak conception rates occurred July-August, with a clear trough shown (with less than 5 per cent of all conceptions occurring) MarchApril. These data, as they correlate with (adjusted) rainfall and livestock milk production, are expressed in Figure 2.

Evidence that falls contrary to the above is shown in studies of the Efe people of Zaire and of !Kung San people in Namibia (Bentley 1985; Ellison et al. 1989). Compared to the above populations, these showed a highly reduced birth seasonality, with a lack of hormonal or ovulatory frequency fluctuation, despite their parallel geographic location. This contradiction highlights an important parameter of seasonality: subsistence type. The more constant birth rates of the Efe and !Kung populations can be explained by their forage-based subsistence type. With no dependence on rainfall for crop productions or livestock health, ERO in these populations is much less prominent, as female energy balance is not as affected by food availability according to rainfall (Bentley 1985). This evidence thus reinforces the following conclusions: 1) ERO is the result of energy imbalance due to food availability as affected by rainfall and 2) ERO has a significant impact on seasonality of conception, and thus birth rates. It can thus be seen that ERO in sub-Saharan tropical African agriculturalist and pastoralist populations is caused by fluctuations in rainfall, which affect food availability. 


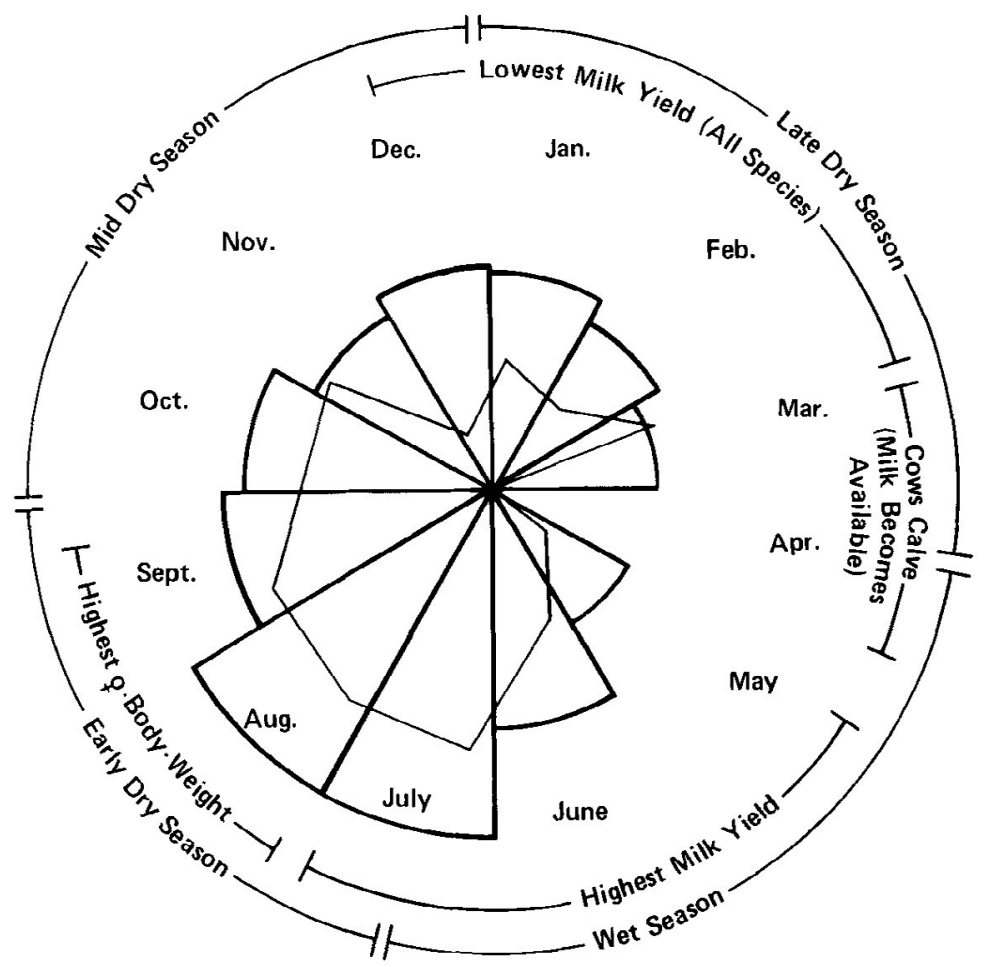

Conceptions
Rainfall Rotated $109^{\circ}$ (3.6 Month Lag)

Figure 2: Circle graph showing conception rates (bars) according to rainfall (line) in a calendar year, as correlated with seasons and milk production in Turkana pastoralist population

Source: Leslie and Fry 1989:108, Fig. 4 (License no. 3897990628417), reproduced with permission.

\section{Temperate Nepali populations}

In the foothills of the Himalayas live the native Nepalese Tamang people. With the temperate climate in this region, they subsist via agriculturalism with aspects of pastoralism, growing mainly root vegetables and other hardy plants that are not dependent on rainfall. Studies performed on energetic regulation 
of ovulation in the population were performed in collaboration by PanterBrick and Ellison over a period of several years, and followed Ellison's previous research in former Zaire on the Efe and Lese (Panter-Brick et al. 1993). Research here revolved around the significance of food availability in this more temperate, food-constant region. In their studies, Panter-Brick et al. (1993) and Panter-Brick (1996) proposed that an observed energetic imbalance seen in Tamang women would be, for the most part, the result of a different factor-namely increased energy expenditure rather than decreased energy intake. The studies found that ovarian hormone suppression and consequent reduced ovulatory frequency occurred in the population with an increase in workload. When energy expenditure related to subsistence (e.g. harvesting potato crops) increased two-fold, a parallel reduction in Body Mass Index (BMI) occurred. With an increased workload from October to December, Tamang women showed hormonal suppression, which resulted in a 33 per cent decrease in ovulatory frequency (Panter-Brick 1996). Contrastingly, it was found that during periods of hunger, when BMI was also reduced due to reduced energy intake occurring in tandem with reduced workload, ovulatory frequency did not decrease as dramatically (Panter-Brick 1996). Confirming this were data indicating that women in the Tamang population who gained weight during the usual work-heavy monsoon months did not have reduced progesterone levels. As weight is the main indicator of energy balance, these data demonstrate that hormone suppression was not dependent upon nutritional status as such, but energy balance: when energy balance was maintained (and therefore weight was maintained), hormonal levels did not change (Panter-Brick 1996). This observation was crucial in determining that it is not merely reduced nutritional status, but actual negative energy balance that causes ERO in agriculturalist/pastoralist populations, as well as indicating the greater effect of energy expenditure compared to energy intake on ERO in the temperate population.

One important factor to note regarding the study of the Nepali population is the confounding effect of culture and behaviour. A conception trough from October to December was predicted by the ERO, which occurred due to negative energy balance during this period. However, another birth trough seen from March to May was not anticipated by the purely biological model, as maximal weight occurred in the population during this winter period. This second trough is instead explained by behavioural factors, which have an added effect upon the biological factors influencing birth seasonality. To cover them briefly, in the Tamang population, men and women are traditionally separated between the months of March and May. This is because their subsistence work 
takes them to different areas, with the men often out-migrating temporarily for wage-earning work in other regions, while the women undertake the winter agricultural work (Panter-Brick 1996). This fact is acknowledged simply as a footnote: that the birth seasonality seen in the study populations was not wholly the result of biological factors involving ERO.

Overall, the study of the Tamang population shows: 1) ERO resulting in decreased conception rate during particular months occurs as a result of increased energy expenditure leading to negative energy imbalance for women and 2) nonbiological factors also have an influence on this seasonality, and should not be discounted in broader research.

\section{Further directions and current applications}

The area of birth seasonality has recently branched out into more crossdisciplinary fields, and has looked more at consequences of seasonality than causes. These current applications are fundamentally based on the causes of birth seasonality such as the energetic regulation of ovulation, which is this essay's focus. Although it is the author's belief that more recent, thorough research into the various causes of birth seasonality is required, the leap forward caused by the extrapolation of birth seasonality in various other fields is undoubtable. In areas as diverse as epidemiology, sociology, evolutionary biology and wider demography, large-scale birth seasonality models have been found to offer accurate predictions of later outcomes.

In a paper published recently, Dorélien (2016) links the subpopulation results found in studies of sub-Saharan African birth seasonality to larger-scale demographic data, as well as producing aggregate measures across countries and ecological zones to summarise scaled birth rates over the seasons. For epidemiology, this is because of the dependency of infectious disease dynamics upon seasonal mechanisms, which depend on birth seasonality, such as the number of susceptible individuals in a given winter (Dorélien 2016). This is further explored in Martinez-Bakker et al.'s (2014) recent study of childhood disease dynamics in the USA - in this case, measles-according to month of birth.

ERO is a cause of conception seasonality-and therefore to some extent birth seasonality-not only in the case of infectious disease, but in the expression of genes linked with diseases such as diabetes, obesity and eating disorders. This was discussed in Schneider et al. (2012). As indicated therein, the 
differences in hormone secretion, which are caused by the metabolic signals sent during ERO, are shown to have an effect even when conception is successfulthe alteration in hormone levels results in different gene expression.

In wider demography, birth seasonality is important for understanding future mortality and fertility patterns. Supporting this, Dorélien (2015) refers to mortality among young adults in the Gambia, which was found to be increased in those born in the hunger season (Moore et al. 1997), and her own research investigating child mortality in sub-Saharan Africa according to birth month.

As shown, the future direction of this field lies in further investigation into population-characteristic birth seasonality and the resulting demographic trends. The importance of birth seasonality studies is marked by their applicability to a wide range of linked areas. This said, it should be noted that applying biological models of birth seasonality to many current large-scale populations is inappropriate, especially in the developed world. As mentioned, ERO was seen in the referenced agriculturalist and pastoralist populations; though not in populations with different means of subsistence. In many developed countries, the industrial subsistence type means that energy balance remains more constant. For example, with crops transported and grown globally or in temperature- and water-controlled environments, rainfall and seasonality is not a parameter limiting food availability in developed industrialist populations. Similarly, as noted by Panter-Brick (1996) when introducing her study of Tamang women, with much of an industrialist population undertaking no subsistence workload whatsoever, the seasonality of energy expenditure is greatly reduced. However, this does not mean that studies of ERO are useless in such populations. Here, studying ERO is valuable on a more individual or subcultural level. The energy-heavy workloads of elite athletes and, in particular, the combination of this with low energy intake in ballerinas has been increasingly studied recently (Louks 2013; Fontana and della Torre 2016), and poses some interesting questions regarding the limits to fecundity in these subcultures, offering another context and direction that this aspect of birth seasonality may take in the future.

\section{Conclusions}

Comparing birth seasonality as a result of ERO in temperate and tropical subpopulations highlights the complexity of mechanisms regulating birth seasonality. In terms of the effects of ERO, the following trends were seen. 
In the tropical African populations, the effect of ERO is seen as troughs in conception rates during their respective preharvest months, when low rainfall and crop maturity reduces food availability. The resulting negative energy balance caused by reduced energy intake is clearly correlated to reduced frequency of ovulation and conception. This can be compared to peaks in these rates after successful harvest in late July to September, when an increase in energy intake results in positive energy balance and hence increased ovulatory frequency (Bailey et al. 1992).

Contrastingly, in the temperate Nepali population, workload increase during the harvest creates an energy imbalance that results in a trough in conceptions from October to December, as the increased energy expenditure tips the energy balance to negative. The expected subsequent peak in conception rates later in the year is somewhat mitigated by nonbiological factors, although it is evident that, biologically speaking, the reduction in workload results in energetic rebalance. Thus there is a return to regular ovulatory patterns, with seasonality of conception being due to behavioural factors only (Panter-Brick 1996).

The wide-ranging impacts of birth month on population health and mortality are evidently linked to many different fields, as has been further investigated recently. This underlines the importance of understanding the biological mechanisms such as the energetic regulation of ovulation that cause birth seasonality, and how these differ between populations. Through gaining a fundamental understanding of the causes of birth seasonality, its consequences can be investigated from a more nuanced perspective.

\section{Acknowledgements}

I would like to take the opportunity to acknowledge the editing contributions of my lecturer and editor, Dr Geoff Kushnick, and to thank him for his advice.

\section{References}

Bailey RC, Jenike MR, Ellison PT, Bentley GR, Harrigan AM, Peacock NR. 1992. The ecology of birth seasonality among agriculturalists in central Africa. J Biosoc Sci. 24(3):393-412. doi.org/10.1017/ S0021932000019957 
Bantje H. 1987. Seasonality of births and birth weights in Tanzania. Soc Sci Med. 24(9):733-739. doi.org/10.1016/0277-9536(87)90110-9

Bentley GR. 1985. Hunter-gather energetics and fertility: A reassessment of the !Kung San. Hum Ecol. 13(1):71-109. doi.org/10.1007/BF01531090

Berga S, Naftollin F. 2012. Neuroendocrine control of ovulation. Gynecol Endrocrinol. 28(1):9-13. doi.org/10.3109/09513590.2012.651929

Bongaarts J. 1978. A framework for analysing the proximate determinants of fertility. Popul Deve Rev. 4(1):105-132. doi.org/10.2307/1972149

Condon RG. 1991. Birth seasonality, photoperiod, and social change in the Central Canadian Arctic. Hum Ecol. 19(3):287-321. doi.org/10.1007/ BF00888980

Dorélien AM. 2015. Effects of birth month on child health and survival in sub-Saharan Africa. Biodemography Soc Biol. 61(2):209-230. doi.org/10 $.1080 / 19485565.2015 .1032399$

Dorélien AM. 2016. Birth seasonality in sub-Saharan Africa. Demographic Res. 34:761-796. doi.org/10.4054/DemRes.2016.34.27

Dorélien AM, Ballesteros S, Grenfell BT. 2013. Impact of birth seasonality on acute immunizing infections in sub-Saharan Africa. PLoS ONE. 8(10):e75806. doi.org/10.1371/journal.pone.0075806

Ellison PT. 2003. Energetics and reproductive effort. Am J Hum Biol. 15(3):342-351. doi.org/10.1002/ajhb.10152

Ellison PT, Peacock NR, Panter-Brick CM. 1989. Ecology and ovarian function among Lese women of the Ituri forest, Zaire. Am J Phys Anthropol. 78(4):159-526. doi.org/10.1002/ajpa.1330780407

Fontana R, della Torre S. 2016. The deep correlation between energy metabolism and reproduction: A view on the effects of nutrition for women's fertility. Nutrients. 8(2):87-121. doi.org/10.3390/nu8020087

Leslie PW, Fry PH. 1989. Extreme seasonality of births among nomadic Turkana pastoralists. Am J Phys Anthropol. 79(1):103-115. doi.org/ 10.1002/ajpa.1330790111 
Louks AB. 2013. Exercise training in the normal female: Effects of low energy availability on reproductive function. In: M Constantini, A Hackney, editors. Endocrinology of physical activity and sport. 2nd ed. New York (NY): Humana Press. pp. 185-205. doi.org/10.1007/978-1-62703-314$5 \_11$

Martinez-Bakker M, Bakker K, King A, Rohani P. 2014. Human birth seasonality: Latitudinal gradient and interplay with childhood disease dynamics. Proc R Soc B. 281(1783): 20132438. doi.org/10.1098/ rspb.2013.2438

Moore SE, Cole TJ, Poskitt EM, Sonko BJ, Whitehead RG, McGregor IA, Prentice AM. 1997. Season of birth predicts mortality in rural Gambia. Nature. 388(6641):434. doi.org/10.1038/41245

Panter-Brick C. 1996. Proximate determinants of birth seasonality and conception failure in Nepal. J Pop Stud. 50(2):203-220. doi.org/10.1080/ 0032472031000149306

Panter-Brick CM, Lotstein DS, Ellison PT. 1993. Seasonality of reproductive function and weight loss in rural Nepali women. Hum Reprod. 8(5):684690. doi.org/10.1093/oxfordjournals.humrep.a138120

Philibert A, Tourigny C, Coulibaly A, Fournier P. 2013. Birth seasonality as a response to a changing rural environment (Kayes region, Mali). J Biosoc Sci. 45(4):547-565. doi.org/10.1017/S0021932012000703

Rhinehart E. 2016. Mechanisms linking energy balance and reproduction: Impact of prenatal environment. Horm Mol Biol Clin Investig. 25(1):1868-1883. doi.org/10.1515/hmbci-2016-0004

Schneider J, Klingerman C, Abdulhay A. 2012. Sense and nonsense in metabolic control of reproduction. Front Endocrinol. 3:26. doi.org/ $10.3389 /$ fendo.2012.00026

Wargentin P. 1767. Uti hvilka Manader flera Maniskor arligen foda och do i Sverige. Mem Sci Acad Sweden. 27:249-258. 
This text is taken from the The Human Voyage: Undergraduate Research in Biological Anthropology: Volume 1, 2017, edited by Alison Behie, published 2017 by ANU eView, The Australian National University, Canberra, Australia.

dx.doi.org/10.22459/HV.01.2017.03 